Systematic Review

\title{
The Role of Unilateral Balloon Kyphoplasty for the Treatment of Patients with OVCFS: A Systematic Review and Meta-Analysis
}

Guang-Heng Xiang, MD', Min-Ji Tong, MD', Chao Lou, MD², Si-Pin Zhu, MD', Wei Jun Guo, MD', and Chen Rong Ke, MD ${ }^{1}$

From: ${ }^{1}$ Department of Orthopaedic Surgery, The Second Affiliated Hospital and Yuying Children's Hospital of Wenzhou Medical University, Wenzhou, Zhejiang, China; ${ }^{2}$ Department of Orthopaedic Surgery, The Fifth Affiliated Hospital of Wenzhou Medical University, Lishui Central Hospital, Lishui, Zhejiang, China

Address Correspondence: Chen Rong Ke, MD Department of Orthopaedic Surgery

The Second Affiliated Hospital and Yuying Children's Hospital of Wenzhou Medical University 109 Xeuyuanxi Road Wenzhou, China E-mail:

xiangguanghen@wmu.edu.com

Disclaimer: There was no external funding in the preparation of this manuscript. Conflict of interest: Each author certifies that he or she, or a member of his or her immediate

family, has no commercial association (i.e., consultancies, stock ownership, equity interest, patent/licensing arrangements, etc.) that might pose a conflict of interest in connection with the submitted manuscript.

Manuscript received: 06-02-2017 Revised manuscript received: 09-14-2017

Accepted for publication: 11-16-2017

Free full manuscript: www.painphysicianjournal.com
Background: An increasing number of studies have been conducted to apply unilateral balloon kyphoplasty in the treatment of ostroporotic vertebral compression fractures (OVCFs). However, the efficacy and safety of unilateral kyphoplasty and whether a unilateral or a bilateral approach is superior is controversial.

Objectives: The purpose of this study was to evaluate the role of unilateral balloon kyphoplasty and use meta-analysis to compare the efficacy and safety of unilateral and bilateral kyphoplasty in patients with OVCFs.

Study Design: A systematic literature search was conducted from 1970 to April 2017 using Medline database and the Cochrane Central Register of Controlled Trials. Articles were limited to those published in English. Randomized controlled trials and nonrandomized comparative studies were also included.

Setting: The following search terms were used: "osteoporotic vertebral compression fractures," or "OVCF," and "unilateral kyphoplasty," or "unipedicular approach," or "single balloon kyphoplasty," or "one balloon kyphoplasty." A comprehensive search of reference lists of retrieved articles and previous published reviews was also performed to ensure inclusion of all possible studies.

Methods: All potential articles were independently reviewed by 2 investigators for inclusion into the final analysis. MINORS score was used for nonrandomized studies, and Detsky quality index was applied for prospective randomized controlled trials. Systematic review and meta-analysis was performed for the included studies.

Results: After unilateral balloon kyphoplasty the mean postoperative visual analog score (VAS) was from 1.74 to 4.77 , mean postoperative kyphotic angle was from $5.9^{\circ}$ to $11.22^{\circ}$, and complications involving cement leaks was from 6.8 to $21.9 \%$ or adjacent level fractures was from 0 to $5.6 \%$ ) Unilateral kyphoplasty had significantly lower operative time, and less bone cement volume; however, the postoperative VAS, Oswestry Disability Index (ODI), vertebral height restoration rate, and cement leakage and adjacent vertebral fracture rate, were similar to bilateral kyphoplasty.

Limitations: Only 6 randomized controlled trials and 3 retrospective comparative studies were selected for analysis. Heterogeneity was detected among the studies when we pooled the outcomes.

Conclusions: Based on the available evidence, the clinical and radiological results of unilateral balloon kyphoplasty were as good as those of bilateral balloon kyphoplasty for the treatment of OVCFs. And unilateral kyphoplasty had advantages in terms of operation time, radiation exposure, and cost.

Key words: Unilateral balloon kyphoplasty, bilateral balloon kyphoplasty, osteoporotic vertebral compression fractures, complications of balloon kyphoplasty, meta-analysis

Pain Physician 2018; 21:209-218 
$\mathrm{V}$ ertebral compression fractures constitute a major health problem affecting more than 1.4 million people each year worldwide, leading to pain, significant morbidity, and healthcare expenses (12). Minimally invasive techniques, such as percutaneous balloon kyphoplasty, have been employed to treat osteoporotic vertebral compression fractures (OVCFs). Studies have shown that balloon kyphoplasty provides satisfactory clinical outcomes and better efficacy than conservative treatment (3-9). The standard technique for kyphoplasty involves cannulating both pedicles and placing 2 balloons into the vertebral body (bipedicular approach) (10). But recently a unipedicular approach has been advocated, reducing the operating time, radiation exposure, and complications, and increasing the cost-effectiveness of the procedure $(11,12)$. An increasing number of studies have been conducted to apply unilateral balloon kyphoplasty in the treatment of OVCFs (13-19). Scholars have compared the clinical and radiological results of unilateral and bilateral kyphoplasty approach (20-28). However, the efficacy and safety of unilateral kyphoplasty, or whether a unilateral or a bilateral approach is superior, have been controversial. In the current study, we reviewed the literature evaluating the role of unilateral balloon kyphoplasty and used meta-analysis to compare the efficacy and safety of unilateral and bilateral kyphoplasty in patients with OVCFs.

\section{Methods}

\section{Searching and Selection}

A systematic literature search was conducted up to April 2017 using the Medline database and the Cochrane Central Register of Controlled Trials. Articles were limited to those published in English. Because only a small number of randomized controlled trials were available in the literature, nonrandomized comparative studies (prospective and retrospective) were also included. The following search terms were used: "osteoporotic vertebral compression fractures," or "OVCF," and "unilateral kyphoplasty," or "unipedicular approach," or "single balloon kyphoplasty," or "one balloon kyphoplasty." A comprehensive search of reference lists of retrieved articles and previous published reviews was also performed to ensure inclusion of all possible studies.

The following inclusion criteria were used 1) The study population consisted of patients with OVCFs; 2) The patients received surgeries through unilateral ky- phoplasty or bilateral kyphoplasty; 3) At least one of the following outcomes was reported: operative time, $x$-ray exposure time, cement volume, visual analog score (VAS), Oswestry Disability Index (ODI), kyphotic angle, restoration rate, and loss reduction or height loss rate after the operation, the incidence of the adjacent vertebral fracture, and cement leakage. All potential articles were independently reviewed by 2 investigators (X.G.H, T.M.J) for inclusion into the final analysis.

\section{Data Extraction}

Data were collected based on following categories where available: 1) published year and study design; 2) basic characteristics including inclusion/exclusion criteria, age, gender proportion, enrolled number, surgical modalities, and follow-up duration; 3) baseline comparison information of confounding factors, such as gender, age, surgical level, and concomitant diseases; 4) surgical information, including operative time, intraoperative and postoperative blood loss, intraoperative $x$-ray exposure time, and bone cement volume; 5) preoperative and postoperative outcomes such as VAS, ODI, kyphotic angle, and height loss rate; 6) outcomes improvement at last follow-up including VAS, ODI, kyphotic angle, and height restoration rate; 7) complication types and complication rates.

\section{Quality Assessment}

We applied 2 assessing tools to analyze both the randomized and nonrandomized studies included. MINORS score was used for nonrandomized studies, and Detsky quality index was applied for prospective randomized controlled trials $(29,30)$. Based on the previous published papers, studies scoring $\geq 75 \%$ of the maximum MINORS or Detsky score were designated high quality. Each eligible study was independently reviewed by 2 raters for methodological quality (X.G.H, T.M.J). Inconsistencies were resolved through discussion until a consensus was reached.

\section{Meta-Analysis}

For continuous data (operative time, bone cement volume, VAS, ODI, height restoration rate), the inverse variance method was used for the combination of standardized mean differences (SMD). Binary data (adjacent vertebral fracture, cement leakage) were summarized as risk ratios (RR) and combined using the MantelHaenszel method. Heterogeneity was evaluated using the $\chi^{2}$ test and $\mathrm{I}^{2}$ statistics (considered significant when $P$ value for $\chi^{2}$ test $<0.10$ or $1^{2}>50 \%$ ). Random-effect 
models were applied if the heterogeneity was significant; otherwise fixed-effect models were used. The sensitivity analysis was performed to test the strength and robustness of pooled results by sequential omission of individual studies when necessary. Forest plots were used for the graphical display. The analysis was carried out using the statistical software Review Manager Version 5.0 (Cochrane Collaboration, Oxford, UK).

\section{Results}

\section{Literature Search}

The search strategy (Fig. 1) yielded 16 studies on the use of unipedicular balloon kyphoplasty in the treatment of patients with OVCFs, including 6 randomized controlled trials, 3 retrospective comparative studies, and 7 case series (13-28). Characteristics of each article were given in Table 1 and Table 2 .

\section{Risk of Bias Assessment}

MINORS score was used for nonrandomized studies, and Detsky quality index was applied for randomized controlled trials. The scores vary from 15 to 20 (Table 2). According to the previous published papers scoring $>75 \%$ of the maximum score $(15 / 20$ or $18 / 24)$ were designated high quality, there were 8 high quality studies.

\section{Patients Undergoing Unilateral Percutaneous Kyphoplasty}

Seven studies reported 409 patients undergoing unilateral percutaneous kyphoplasty (13-19). We used a descriptive method for these reports (Table 2). The patient mean age range was 60.3-74 years, and 292 patients were women. The surgical techniques including unilateral transpedicular approach $(13,14)$, unilateral extrapedicular approach (15-19). The mean operative time was $25-37.4$ minutes $(14,15,17)$. The mean cement

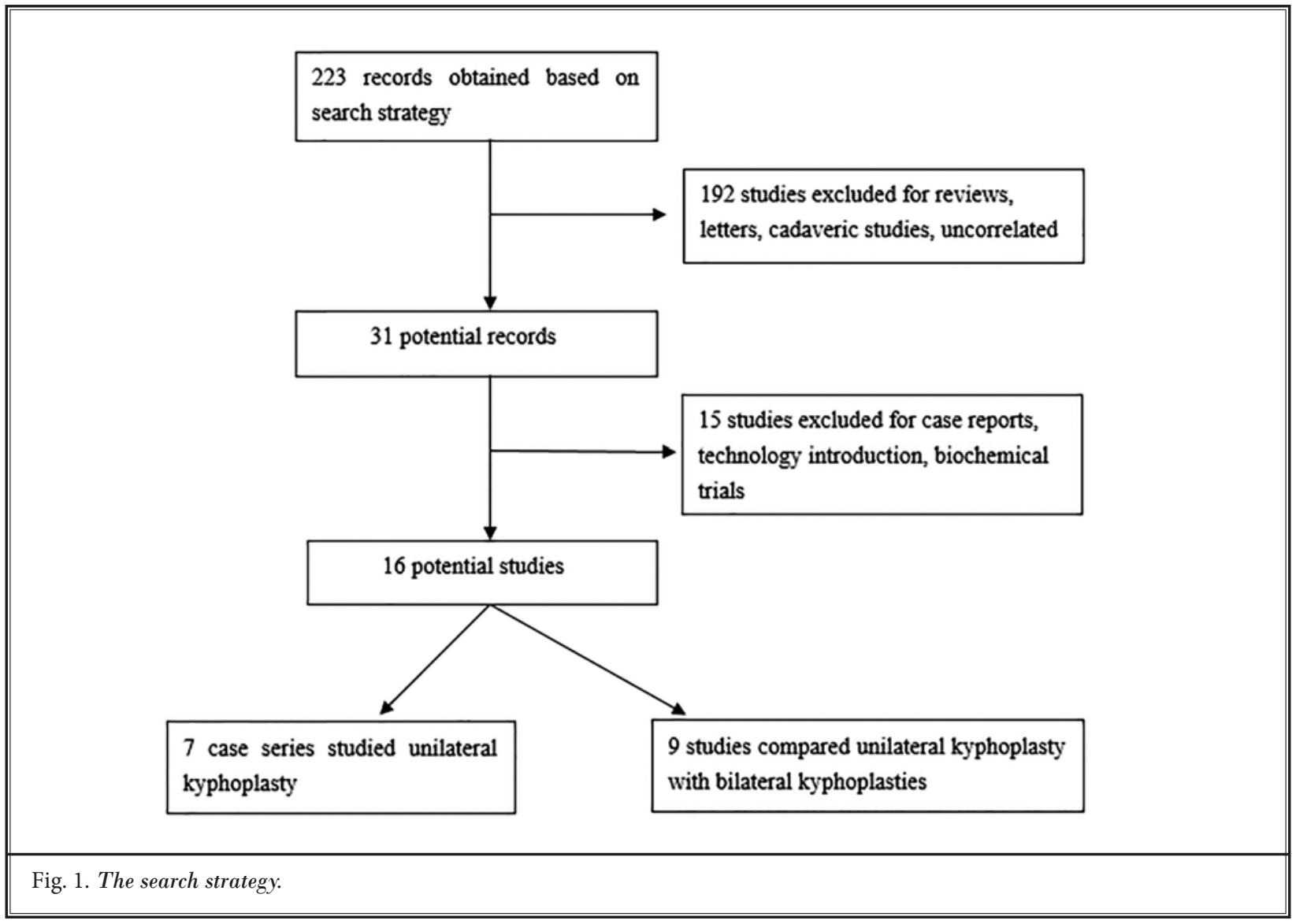


Pain Physician: May/June 2018; 21:209-218

Table 1. Evidence for the use of unilateral balloon kyphoplasty in treatment of OVCFs.

\begin{tabular}{|c|c|c|c|c|c|c|c|}
\hline Characteristic & $\begin{array}{c}\text { Ryu et al } \\
\text { (15) }\end{array}$ & $\begin{array}{l}\text { Lee et al } \\
\text { (13) }\end{array}$ & $\begin{array}{c}\text { Sun et al } \\
(14)\end{array}$ & $\begin{array}{l}\text { Papadopoulos } \\
\text { et al (19) }\end{array}$ & $\begin{array}{c}\text { Ryu et al } \\
\text { (16) }\end{array}$ & $\begin{array}{c}\text { Cho et al } \\
(18)\end{array}$ & $\begin{array}{c}\text { Ge et al } \\
(17)\end{array}$ \\
\hline No. of patients & 31 & 105 & 36 & 142 & 29 & 28 & 38 \\
\hline Mean age $(y)$ & 70 & 71.6 & 73.8 & 74 & 68.8 & 72 & 60.3 \\
\hline Gender (F:M) & $27: 4$ & $80: 25$ & $26: 10$ & $110: 32$ & $23: 6$ & - & $26: 12$ \\
\hline $\mathrm{BMD}(\mathrm{T})$ & $-3.95 \pm 0.97$ & _- & - & & _- & $-3.24 \pm 1.05$ & - \\
\hline Follow-up (mo) & 8.6 & 15.3 & 9.2 & 7.25 & _- & 17.5 & 9.5 \\
\hline Operative time ( $\mathrm{min}$ ) & 25 & $<35$ & 37.4 & - & - & - & 30 \\
\hline Cement volume (mL) & $4.57 \pm 1.03$ & _- & 3.1 & - & $4.90 \pm 1.13$ & $5.12 \pm 1.47$ & $3.2 \pm 1.4$ \\
\hline \multicolumn{8}{|l|}{ Kyphotic angle $\left(^{\circ}\right)$} \\
\hline Pre- & $16.06 \pm 5.24$ & $12.8 \pm 6.1$ & - & - & $15.23 \pm 5.12$ & $11.6 \pm 7.90$ & $19.52 \pm 4.79$ \\
\hline Post- & $8.84 \pm 3.89$ & $7.1 \pm 4.7$ & _ & _ & $8.01 \pm 4.82$ & $5.9 \pm 6.35$ & $11.22 \pm 6.51$ \\
\hline \multicolumn{8}{|l|}{ Cobb angle $\left(^{\circ}\right)$} \\
\hline Pre- & - & $14.8 \pm 8.1$ & $23.43 \pm 5.00$ & _- & - & _- & - \\
\hline Post- & - & $11.8 \pm 9.0$ & $16.16 \pm 2.77$ & - & - & - & - \\
\hline \multicolumn{8}{|l|}{ VAS score } \\
\hline Pre- & $8.58 \pm 1.86$ & $8.7 \pm 1.4$ & $7.27 \pm 1.02$ & $7.02 \pm 2.21$ & $9.24 \pm 1.22$ & $7.7 \pm 1.01$ & $8.92 \pm 0.68$ \\
\hline Post- & $1.78 \pm 1.47$ & $2.3 \pm 0.9$ & $2.71 \pm 0.75$ & $4.77 \pm 2.6$ & $1.74 \pm 1.85$ & $2.0 \pm 1.28$ & $2.80 \pm 0.34$ \\
\hline Cement leaks (n/\%) & $7 / 21.9 \%$ & $9 / 6.8 \%$ & - & $10.73 \%$ & $15.6 \%$ & $3 / 10.7 \%$ & $3 / 7.9 \%$ \\
\hline Adjacent level fractures (n/\%) & - & - & 0 & $8 / 5.6 \%$ & _- & 0 & - \\
\hline $\mathrm{Ha}(\mathrm{mm})$ & \multirow{6}{*}{$\begin{array}{c}\text { Mean } \\
\text { restoration } \\
\text { rate was } \\
31.72 \pm \\
20.98 \%\end{array}$} & & \multirow{6}{*}{$\begin{array}{c}\text { Postoperation } \\
\text { Ha gained } 4.3 \\
\text { mm }\end{array}$} & \multirow{6}{*}{$\begin{array}{c}\text { Mean restoration } \\
\text { rate was } 48.9 \pm \\
36.0 \%\end{array}$} & \multirow{6}{*}{$\begin{array}{l}\text { Mean } \\
\text { restoration } \\
\text { rate was } \\
30.34 \pm \\
20.98 \%\end{array}$} & \multirow{3}{*}{$\begin{array}{c}\text { Mean } \\
\text { restoration } \\
\text { rate was } 11.1 \\
\pm 15.1 \% \\
\end{array}$} & \\
\hline Pre- & & $19.8 \pm 0.24$ & & & & & $18.55 \pm 4.32$ \\
\hline Post- & & $22.1 \pm 0.16$ & & & & & $21.54 \pm 4.32$ \\
\hline $\mathrm{Hm}(\mathrm{mm})$ & & & & & & & \\
\hline Pre- & & $18.5 \pm 0.18$ & & & & $\begin{array}{l}\text { restoration } \\
\text { rate was } 12.8+\end{array}$ & $15.87 \pm 4.43$ \\
\hline Post- & & $22.5 \pm 0.15$ & & & & $12.2 \%$ & $21.52 \pm 3.41$ \\
\hline
\end{tabular}

Pre-: Preoperative; Post-: Postoperative; Ha: Height of anterior vertebral body; Hm: Height of middle vertebral body; VAS: Visual Analog Scale.

Table 2. Characteristics of studies comparing unilateral versus bilateral balloon kyphoplasty.

\begin{tabular}{|l|l|l|l|l|l|l||}
\hline Study & Years & Study design & Quality scale & Gender (F:M) & $\begin{array}{l}\text { Follow-up } \\
(\mathbf{m o})\end{array}$ & Patients \\
\hline Chung HJ et al (24) & 2008 & RCT & $14 / 20$ & $49: 3$ & $\geq 12$ & T11-L2 OVCFs \\
\hline Song BK et al (22) & 2009 & RCS & $16 / 24$ & $29: 16$ & 3 & T6-L4 OVCFs \\
\hline Chen C et al (28) & 2010 & RCT & $16 / 20$ & $58: 0$ & 0.5 & - \\
\hline Chen C et al (21) & 2011 & RCT & $16 / 20$ & $50: 0$ & 24 & T12 or L1 OVCFs \\
\hline Chen L et al (27) & 2011 & RCT & $16 / 20$ & $41: 8$ & 33.5 & T6-L4 OVCFs \\
\hline Wang Z et al (25) & 2012 & RCS & $18 / 24$ & $32: 30$ & $\geq 15.9$ & T9-L5 OVCFs \\
\hline Rebolledo BJ et al (26) & 2013 & RCT & $15 / 20$ & $38: 6$ & 12 & T5-L5 OVCFs \\
\hline Bozkurt M et al (23) & 2014 & RCS & $20 / 24$ & $124: 76$ & 42.2 & T4-L5 OVCFs \\
\hline Yan L et al (20) & 2014 & RCT & $17 / 20$ & $220: 89$ & 16.8 & L1-L5 OVCFs \\
\hline
\end{tabular}

RCS: Retrospective Comparative Study; RCT: Randomized Controlled Trial; OVCFs: Osteoporotic Vertebral Compression Fractures; a RCT was assessed using Detsky score and non-RCT was assessed using MINORS score

volume was 3.1-5.12 mL (14-18). The mean postoperative VAS score was from 1.74 to 4.77 (14-19), and the mean postoperative kyphotic angle was from $5.9^{\circ}$ to $11.22^{\circ}(13,15-18)$. There were 7 case series reported complications involving cement leaks (6.8-21.9\%) or adjacent level fractures (0-5.6\%) (13-19). 


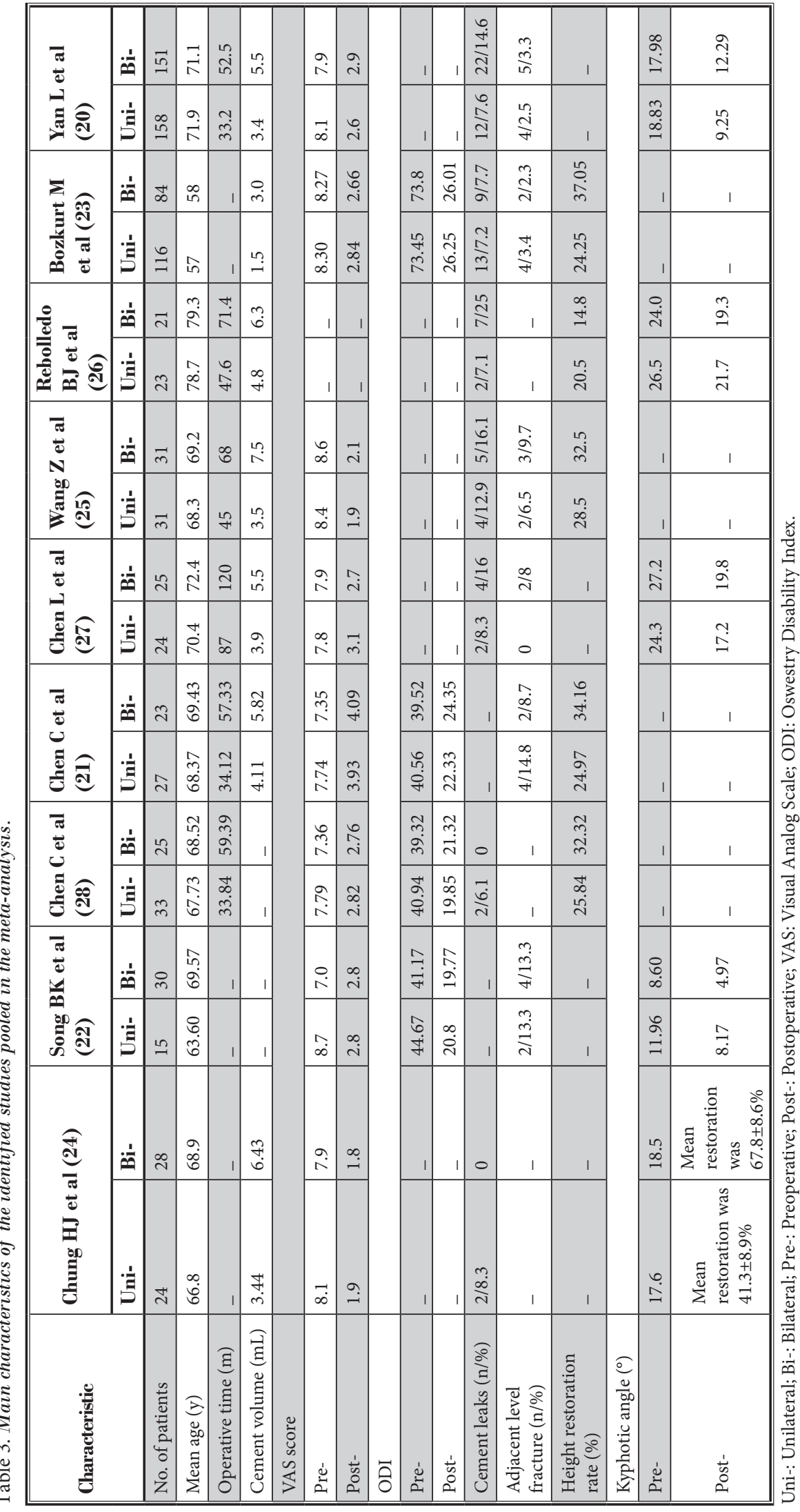




\section{Comparison of Unilateral and Bilateral Percutaneous Kyphoplasty}

Nine studies reported a total of 451 patients in the unilateral kyphoplasty group and 418 in the bilateral kyphoplasty group (20-28). The clinical data of included studies was presented in Table 3.

\section{Operative Time}

Six of them provided adequate data about the mean and SD. The weighted mean difference (WMD) was statistically significant $(\mathrm{WMD}=-23.13, P<0.00001$, $95 \% \mathrm{Cl}:-26.68$ to $-19.58 ; 1^{2}=71 \%$, Fig. 2 ) in favor of the unilateral kyphoplasty group.

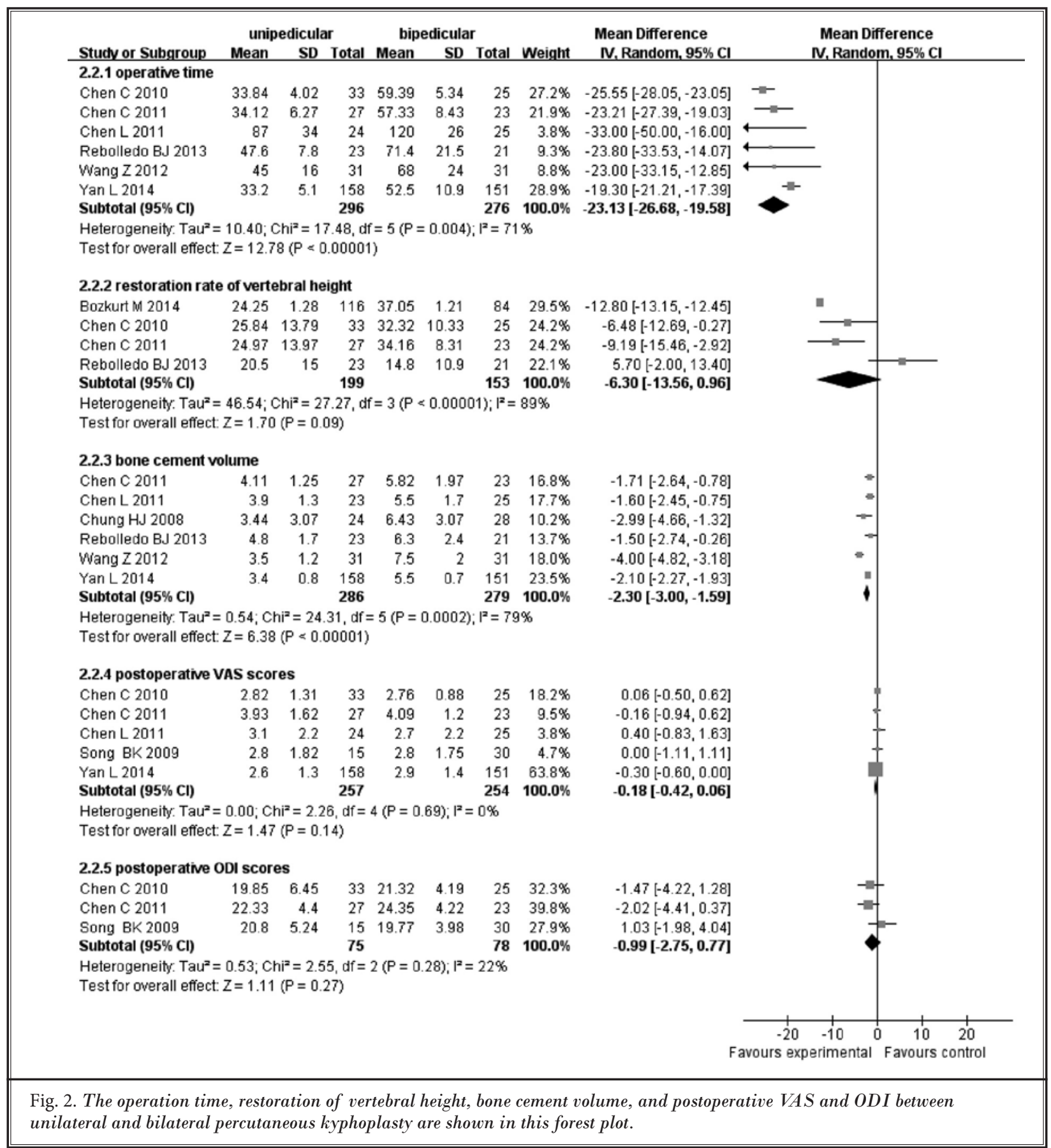




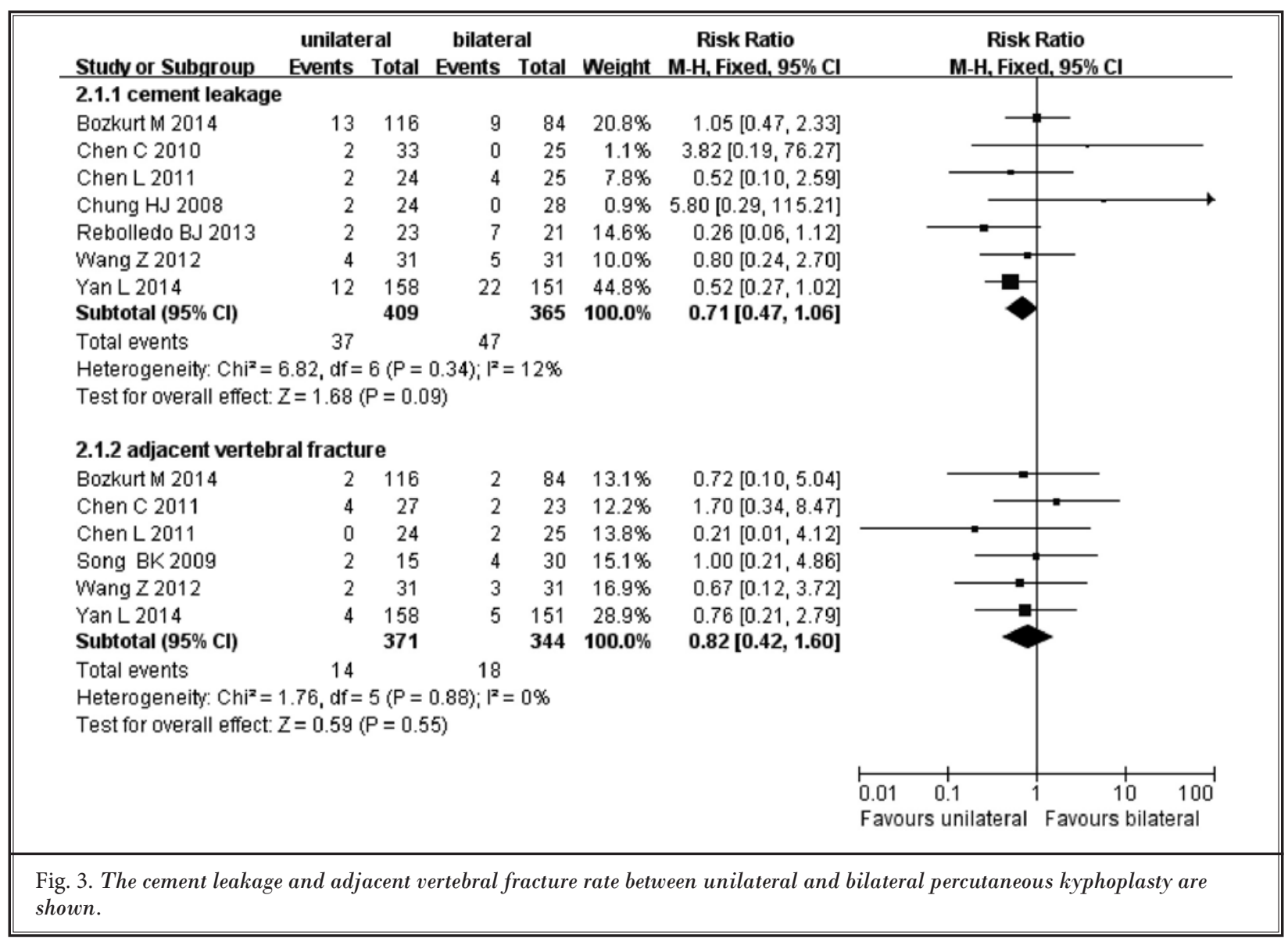

\section{Restoration Rate of Vertebral Height}

Adequate vertebral height restoration data were available in 4 studies. Pooled data indicated a higher restoration rate of vertebral height in the bilateral group, however, the difference was not statistically significant (WMD $=-6.30, P=$ $0.09,95 \%$ Cl: -13.56 to $0.96 ; l^{2}=89 \%$, Fig. 2).

\section{Bone Cement Volume}

Six studies provided adequate data about the mean and SD. Compared with bilateral kyphoplasty group, pooled estimate showed that the unilateral kyphoplasty group used significantly less bone cement volume (WMD $=-2.30, P<0.00001,95 \% \mathrm{Cl}:-3.00$ to $-1.59 ; I^{2}=79 \%$, Fig. 2).

\section{Postoperative VAS and ODI}

Five studies contributed to a summative outcome. The unilateral and bilateral percutaneous kyphoplasty group obtained similar VAS after surgery $(\mathrm{WMD}=-0.18$, $P=0.14,95 \% \mathrm{Cl}:-0.42$ to $0.06 ; \mathrm{I}^{2}=0 \%$, Fig. 2). Three studies reported the results of postoperative ODI, outcomes revealed no difference between unilateral and bilateral percutaneous kyphoplasty (WMD $=-0.99, P=$ $0.27,95 \% \mathrm{Cl}:-2.75$ to $0.77 ; \mathrm{I}^{2}=22 \%$, Fig. 2 ).

\section{Complications}

Data regarding complications were available in 9 studies. Seven studies reported cement leakage, and 6 studies reported adjacent vertebral fracture. The pooled estimate showed that the bilateral group was associated with a higher, but statistically insignificant cement leakage and adjacent vertebral fracture rate when compared with the unilateral group. $(\mathrm{RR}=0.71$, $95 \%$ Cl: $0.47-1.06, P=0.09, I^{2}=12 \% ; R R=0.82,95 \%$ Cl: $0.42-1.6, P=0.55, I^{2}=0 \%$; Fig. 3). No heterogeneity existed among the studies.

\section{Publication Bias}

The funnel plot showed a fairly symmetrical distribution of the studies that reported complication rate. 


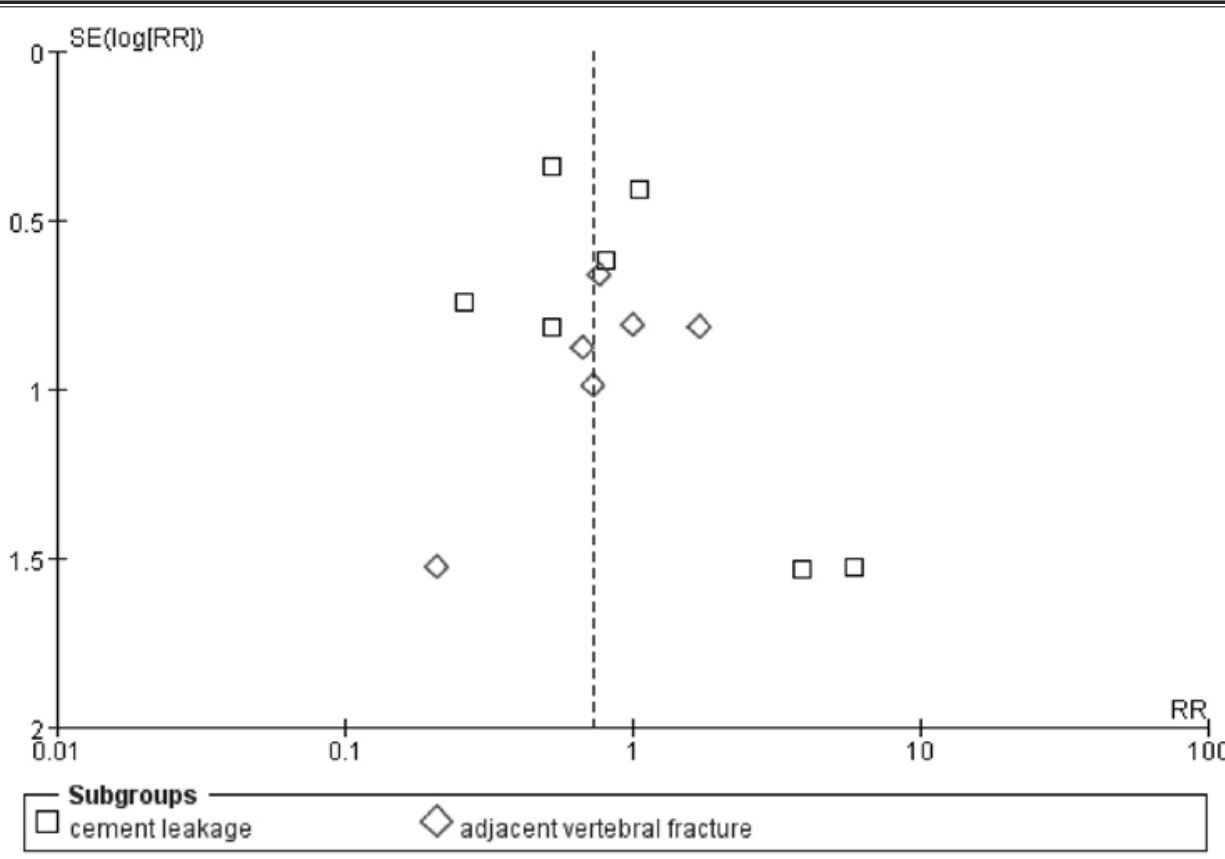

Fig. 4. The funnel plot.

All studies fell within the $95 \% \mathrm{Cl}$ and were distributed evenly about the vertical, implying minimal publication bias (Fig. 4).

\section{Discussion}

Hoh et al (11) introduced the use of balloon kyphoplasty via a unilateral transpedicular approach in the treatment of a T11 OVCF patient. They deemed that the advantages of a unilateral approach included, reducing the risk of pedicle fracture, nerve injury and cement leakage. Additionally, operative and radiation exposure time were decreased as well as the costs of balloon tamps, cannulas, and needles. The biomechanical tests studied by Steinmann et al (31) showed that unipedicular kyphoplasty was comparable to bipedicular kyphoplasty in the restoration of vertebral body strength, stiffness, and height in experimentally induced vertebral compression fractures. Chen et al (32) found that the restoration of biomechanical balance depends on the distribution of cement in unipedicular percutaneous kyphoplasty (PKP). Asymmetrical strengthening in a fractured vertebra may result in unbalanced lumbar mechanics and clinical efficacy will be influenced. However, when cement augmentation crosses the midline and increased stiffness is obtained on both sides, there is a strong potential for biomechanical balance to be achieved. Wang et al (33) introduced the transverse process-pedicle approach, which allowed an easy puncture to meet or surpass the midline of the lumbar vertebral body.

Several studies (34-36) compared clinical outcomes of unilateral and bilateral percutaneous kyphoplasty, but these studies included small sample sizes and some methodological errors. Therefore, we reviewed the literature evaluating the role of unilateral balloon kyphoplasty and used meta-analysis to compare the efficacy and safety of unilateral and bilateral kyphoplasty in patients with OVCFs.

Recently, many reviewers have reported the application of unilateral balloon kyphoplasty in OVCFs (1319). The results showed that the mean postoperative VAS was from 1.74 to 4.77 , and the mean postoperative kyphotic angle was from $5.9^{\circ}$ to $11.22^{\circ}$. These studies also demonstrated complications involving cement leaks (6.8-21.9\%) or adjacent level fractures (0-5.6\%). The clinical and radiographic results confirmed that unilateral balloon kyphoplasty was an effective procedure for the treatment of OVCFs.

Our meta-analysis suggested that: 1) unilateral kyphoplasty had significantly lower operative time, and 
less bone cement volume; 2 ) the postoperative VAS and ODI were similar between these 2 groups; 3 ) there was no significant difference in vertebral height restoration; 4) there was no significant difference in cement leakage or adjacent vertebral fracture rate. Owing to the use of only one balloon, cannula, and needle, the cost was less for the unilateral kyphoplasty group.

\section{Limitations}

There are several limitations in this meta-analysis. First, only 6 randomized controlled trials and 3 retrospective comparative studies were selected for analysis. Therefore, the level of evidence for this meta-analysis was not high. Second, heterogeneity was detected among the studies when we pooled the outcomes.
The heterogeneity could be explained by various study qualities, study designs, and patients' baselines. Third, incomplete data recording was observed when we extracted clinical outcomes. Pooling of such data might lead to bias. Despite these weaknesses, our study can still provide some value for clinical reference.

\section{Conclusions}

Based on the available evidence, the clinical and radiological results of unilateral balloon kyphoplasty were as good as those of bilateral balloon kyphoplasty for the treatment of OVCFs. Unilateral kyphoplasty had advantages in terms of operation time, radiation exposure, and cost. More randomized controlled trials are needed to compare these 2 surgical options.

\section{References}

1. Johnell O, Kanis JA. An estimate of the worldwide prevalence and disability associated with osteoporotic fractures. Osteoporos Int 2006; 17:1726-1733.

2. Kado DM, Duong T, Stone KL, Ensrud KE, Nevitt MC, Greendale GA, Cummings SR. Incident vertebral fractures and mortality in older women: A prospective study. Osteoporos Int 2003; 14:589-594.

3. Garfin SR, Yuan HA, Reiley MA. New technologies in spine: Kyphoplasty and vertebroplasty for the treatment of painful osteoporotic compression fractures. Spine 2001; 26:1511-1515.

4. Wardlaw D, Cummings SR, Van Meirhaeghe J, Bastian L, Tillman JB, Ranstam J, Eastell R, Shabe P, Talmadge $\mathrm{K}$, Boonen S. Efficacy and safety of balloon kyphoplasty compared with nonsurgical care for vertebral compression fracture (FREE): A randomised controlled trial. Lancet 2009; 373:1016-1024.

5. Wang G, Yang H, Meng B, Zhu X, Zou J, Gan M, Mei X, Chen K, Tang T. Posttraumatic osteoporotic vertebral osteonecrosis treated using balloon kyphoplasty. J Clin Neurosci 2011; 18:664-668.

6. Boonen S, Van Meirhaeghe J, Bastian L, Cummings SR, Ranstam J, Tillman JB, Eastell R, Talmadge K, Wardlaw D. Balloon kyphoplasty for the treatment of acute vertebral compression fractures: 2-year results from a randomized trial. J Bone Miner Res 2011; 26:1627-1637.

7. Berlemann U, Franz T, Orler R, Heini PF. Kyphoplasty for treatment of osteoporotic vertebral fractures: A prospective non-randomized study. Eur Spine ] 2004; 13:496-501.

8. Ledlie JT, Renfro M. Balloon kyphoplasty: One-year outcomes in vertebral body height restoration, chronic pain, and activity levels. J Neurosurg 2003; 98:36-42.

9. Boszczyk BM, Bierschneider M, Hauck S, Beisse R, Potulski M, Jaksche H. Transcostovertebral kyphoplasty of the mid and high thoracic spine. Eur Spine J 2005; 14:992-999.

10. Theodorou DJ, Theodorou SJ, Duncan TD, Garfin SR, Wong WH. Percutaneous balloon kyphoplasty for the correction of spinal deformity in painful vertebral body compression fractures. Clin Imaging 2002; 26:1-5.

11. Hoh BL, Rabinov JD, Pryor JC, Hirsch JA. Balloon kyphoplasty for vertebral compression fracture using a unilateral balloon tamp via a uni-pedicular approach: Technical note. Pain Physician 2004; 7:111-114.

12. Hu MM, Eskey CJ, Tong SC, Nogueira RG, Pomerantz SR, Rabinov JD, Pryor JC, Hirsch JA. Kyphoplasty for vertebral compression fracture via a uni-pedicular approach. Pain Physician 2005; 8:363-367.

13. Lee SB, Cho KS, Huh PW, Yoo DS, Kang SG, Kim DS, Park CK. Clinical and radiographic results of unilateral transpedicular balloon kyphoplasty for the treatment of osteoporotic vertebral compression fractures. Acta Neurochir Suppl 2008; 101:157-160.

14. Sun G, Jin P, Li FD, Liu XW, Hao RS, Yi $Y H$, Xie ZY. Preliminary study on a sin- gle balloon cross-midline expansion via unipedicular approach in kyphoplasty. Chin Med J (Engl) 2008; 121:1811-1814.

15. Ryu KS, Park CK, Kim MK, Kim DH. Single balloon kyphoplasty using far-lateral extrapedicular approach: Technical note and preliminary results. J Spinal Disord Tech 2007; 20:392-398.

16. Ryu KS, Huh HY, Jun SC, Park CK. Single-balloon kyphoplasty in osteoporotic vertebral compression fractures: Farlateral extrapedicular approach.J Korean Neurosurg Soc 2009; 45:122-126.

17. Ge Z, Ma R, Chen Z, Zhang H, Ding H, Liang S, Suo Z. Uniextrapedicular kyphoplasty for the treatment of thoracic osteoporotic vertebral fractures. Orthopedics 2013; 36:e1020-e1024.

18. Cho SM, Nam YS, Cho BM, Lee SY, Oh SM, Kim MK. Unilateral extrapedicular vertebroplasty and kyphoplasty in lumbar compression fractures: Technique, anatomy and preliminary results. J Korean Neurosurg Soc 2011; 49:273-277.

19. Papadopoulos EC, Edobor-Osula F, Gardner MJ, Shindle MK, Lane JM. Unipedicular balloon kyphoplasty for the treatment of osteoporotic vertebral compression fractures: Early results. J Spinal Disord Tech 2008; 21:589-596.

20. Yan L, Jiang R, He B, Liu T, Hao D. A comparison between unilateral transverse process-pedicle and bilateral puncture techniques in percutaneous kyphoplasty. Spine 2014; 39:B19-B26.

21. Chen C, Wei H, Zhang W, Gu Y, Tang G, Dong R, Xu Y, Chen L. Comparative 
study of kyphoplasty for chronic painful osteoporotic vertebral compression fractures via unipedicular versus bipedicular approach. J Spinal Disord Tech 2011; 24:E62-E65.

22. Song BK, Eun JP, Oh YM. Clinical and radiological comparison of unipedicular versus bipedicular balloon kyphoplasty for the treatment of vertebral compression fractures. Osteoporos Int. 2009; 20:1717-1723.

23. Bozkurt M, Kahilogullari G, Ozdemir M, Ozgural O, Attar A, Caglar S, Ates Cet. Comparative analysis of vertebroplasty and kyphoplasty for osteoporotic vertebral compression fractures. Asian Spine ] 2014; 8:27-34.

24. Chung HJ, Chung KJ, Yoon HS, Kwon $\mathrm{IH}$. Comparative study of balloon kyphoplasty with unilateral versus bilateral approach in osteoporotic vertebral compression fractures. Int Orthop 2008; 32:817-820.

25. Wang Z, Wang G, Yang H. Comparison of unilateral versus bilateral balloon kyphoplasty for the treatment of osteoporotic vertebral compression fractures. J Clin Neurosci 2012; 19:723-726.

26. Rebolledo BJ, Gladnick BP, Unnanuntana A, Nguyen JT, Kepler CK, Lane JM. Comparison of unipedicular and bipedicular balloon kyphoplasty for the treatment of osteoporotic vertebral compression fractures: A prospective randomised study. Bone Joint J 2013; 95-B:401-406.

27. Chen L, Yang H, Tang T. Unilateral versus bilateral balloon kyphoplasty for multilevel osteoporotic vertebral compression fractures: A prospective study. Spine 2011; 36:534-540.

28. Chen C, Chen L, Gu Y, Xu Y, Liu Y, Bai X, Zhu X, Yang H. Kyphoplasty for chronic painful osteoporotic vertebral compression fractures via unipedicular versus bipedicular approachment: A comparative study in early stage. Injury 2010; 41:356-359.

29. Slim K, Nini E, Forestier D, Kwiatkowski F, Panis Y, Chipponi J. Methodological index for non-randomized studies (minors): Development and validation of a new instrument. ANZ J Surg 2003; 73:712-716.

30. Detsky AS, Naylor CD, O'Rourke K, McGeer AJ, L'Abbe KA. Incorporating variations in the quality of individual randomized trials into meta-analysis. J Clin Epidemiol 1992; 45:255-265.

31. Steinmann J, Tingey CT, Cruz G, Dai Q. Biomechanical comparison of unipedicular versus bipedicular kyphoplasty. Spine 2005; 30:201-205.
32. Chen B, Li Y, Xie D, Yang X, Zheng Z. Comparison of unipedicular and bipedicular kyphoplasty on the stiffness and biomechanical balance of compression fractured vertebrae. Eur Spine ] 2011; 20:1272-1280.

33. Wang S, Wang Q, Kang J, Xiu P, Wang G. An imaging anatomical study on percutaneous kyphoplasty for lumbar via a unilateral transverse process-pedicle approach. Spine 2014; 39:701-706.

34. Sun H, Lu PP, Liu YJ, Yang I, Zhou PH, Shen XF, Sun SW, Yang H. Can unilateral kyphoplasty replace bilateral kyphoplasty in treatment of osteoporotic vertebral compression fractures? A systematic review and meta-analysis. Pain Physician 2016; 19:551-563.

35. Feng $\mathrm{H}$, Huang $P$, Zhang $X$, Zheng $G$, Wang Y. Unilateral versus bilateral percutaneous kyphoplasty for osteoporotic vertebral compression fractures: A systematic review and meta-analysis of RCTs. J Orthop Res 2015; 33:1713-1723.

36. Cheng $X$, Long $\mathrm{HQ}, \mathrm{Xu} \mathrm{JH}$, Huang J L, Li FB. Comparison of unilateral versus bilateral percutaneous kyphoplasty for the treatment of patients with osteoporosis vertebral compression fracture (OVCF); A systematic review and meta-analysis. Eur Spine J 2016; 25:3430-3449. 